\title{
IDENTIFIKASI KARAKTER KUALITATIF BEBERAPA GALUR UJI CABAI RAWIT (Capsicum frutescens L.) IPB DI KOTA PALEMBANG
}

\author{
Qualitative Characters Identification of Some IPB Cayenne Pepper \\ (Capsicum frutescens L.) Lines in Palembang City
Karlin Agustina $^{a^{*},}$, Yursida ${ }^{a}$, Evriani Mareza ${ }^{a}$, Elvira Belinda Adisma ${ }^{a}$, Muhamad Syukur ${ }^{b}$
${ }^{a}$ Staf Pengajar Program Studi Agroteknologi, Fakultas Pertanian Universitas IBA Palembang
Jl. Mayor Ruslan, 9 Ilir, Kec. Ilir Tim. II, Kota Palembang, Sumatera Selatan 30164

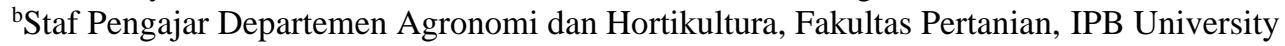
Jl. Raya Dramaga, Kampus IPB Dramaga, Bogor 16680, Indonesia
*Email korespondensi: karlinagustina_92@yahoo.co.id

\section{Diterima 21 Maret 2021/Disetujui 25 April 2021}

\begin{abstract}
ABSTRAK
Penelitian ini bertujuan untuk mengidentifikasi karakter kualitatif galur-galur uji cabai rawit IPB di Kota Palembang. Penelitian dilaksanakan pada September 2018-April 2019 di Kecamatan Sematang Borang, Kota Palembang. Rancangan penelitian yang digunakan adalah Rancangan Acak Kelompok (RAK) satu faktor, yaitu 11 galur uji cabai rawit (F5285290-237-6-1, F6285290-6-10-1-1, F5285290-290-2-1, F5285290-290-9-1, F5285290-290-9-3, F5321290-40-2-1, F5285290-123-6-15, F6321290-252-10-8-4, F5285290-38-6-3, F6321290-252-10-8-23, F6321290-252-10-8-7) dan 5 galur pembanding (Bonita IPB, C290, C285, C295, C321) digunakan sebagai perlakuan. Satu satuan percobaan berupa plot dengan ukuran $5 \mathrm{~m}$ x $1 \mathrm{~m}$ yang terdiri atas 10 tanaman contoh. Identifikasi karakter kualitatif dicocokkan dengan kriteria deskripsi cabai menurut IPGRI (1995) dan Direktorat Perbenihan Hortikultura (2017). Hasil evaluasi menunjukkan 100\% galur uji dan galur pembanding cabai rawit memiliki kesamaan dalam bentuk batang bersudut, warna batang hijau muda, bentuk daun oval, warna bunga putih kehijauan, kelopak dan mahkota bunga berwarna hijau dan putih kehijauan. Warna daun galur cabai rawit hijau dan hijau muda. Kepala putik berwarna hijau muda, hijau, kuning kehijauan dan kuning. Benang sari berwarna ungu dan putih bergaris ungu. Buah cabai muda memiliki warna kulit yang berbeda dengan buah tua. Warna kulit buah muda bervariasi antara putih, hijau kekuningan dan hijau muda, sedangkan warna kulit buah tua bervariasi antara merah, merah terang dan merah tua. Bentuk potongan melintang buah segitiga-segitiga sempit. Bentuk biji ginjal atau bulat pipih, dengan warna biji kekuningan dan putih kekuningan.
\end{abstract}

Kata kunci: deskripsi, keragaman, morfologi

\section{ABSTRACT}

The research aimed to identify the qualitative characters of IPB's cayenne pepper test lines in Palembang City. The research was conducted in September 2018-April 2019 in Sematang Borang District, Palembang City. The experiment was arranged in a randomized completely block design (RCBD) with 11 cayenne pepper test lines (F5285290-237-6-1, F6285290-6-10-1-1, F5285290-290-2-1, F5285290-290-9-1, F5285290-290-9-3, F5321290-40-2-1, F5285290-123-6-15, F6321290-252-10-8-4, F5285290-38-6-3, F6321290-252-10-8-23, F6321290-252-10-8-7) and 5 controls lines (Bonita IPB, C290, C285, C295, C321) were used as treatments. One experimental unit was a plot measuring $5 \mathrm{~m} \times 1 \mathrm{~m}$ which consisted of 10 sample plants per plot. Qualitative characters identification was based on chili description criteria according to IPGRI (1995) and the Directorate of Horticultural Seeds (2017). The evaluation results showed that 100\% cayenne pepper test lines and controls have similarities in the form of an angled stem shape, light green stem color, ovate leaf shape, white-green flower color, green calyx, white-green corolla. The leaves were green and light green. Stigmas were green, light green, green-yellow and yellow. Filaments were purple and white striped purple. The fruit color at intermediate stage was diffrent with mature stage. The fruit color at intermediate stage varied from white, green-yellow, to light-green, while at mature stage the fruit color varied from red, light red to dark red. Shape of fruit cross section is triangular-narrow triangular fruit shape. Seed shape between the kidneys to Flat round with yellow and yellow-white color. 


\section{PENDAHULUAN}

Cabai merupakan salah satu komoditas hortikultura unggulan (Direktorat Jenderal Hortikultura 2008). Masyarakat Indonesia umumnya mengenal dua jenis cabai, yaitu cabai besar dan cabai kecil atau rawit. Cabai rawit merupakan salah satu jenis sayur buah yang digemari dan banyak dikonsumsi sebagai bumbu masakan dan dipercaya dapat meningkatkan selera makan bagi sebagian orang (Safira 2011). Terdapat dua jenis cabai rawit yang banyak dikonsumsi masyarakat, yaitu cabai rawit hijau yang termasuk ke dalam spesies Capsicum annum dan cabai rawit merah yang termasuk spesies Capsicum frutescens. Cabai rawit merah memiliki rasa lebih pedas memiliki kombinasi warna, rasa, dan nilai nutrisi yang lengkap serta nilai ekonomi tinggi (Setiadi 1999; Kouassi et al. 2012). Laporan BPS (2017) menunjukkan cabai rawit sangat digemari masyarakat Indonesia, sehingga pada tahun 2015 rata-rata konsumsi cabai rawit per kapita per bulan mencapai $0,06 \mathrm{~kg}$.

Menurut BPS (2015), produktivitas rata-rata tanaman cabai rawit mencapai 6,45 ton.ha ${ }^{-1}$. Peningkatan penggunaan cabai sebagai bahan makanan sebesar $10,87 \%$ terjadi setiap tahun dan di tahun 2014 total penggunaan cabai sebagai bahan makanan sebesar 1,93 juta ton. Kondisi permintaan cabai yang tinggi tidak mampu diimbangi dengan baik oleh produksi nasional, karena terdapat kekurangan sebesar 49.925 ton cabai di tahun 2014 (Pusat Data dan Sistem Informasi Kementerian Pertanian 2016). Hal ini mendorong usaha peningkatan produktivitas untuk memenuhi permintaan pasar. Upaya meningkatkan produktivitas tanaman cabai rawit salah satunya melalui perakitan varietas unggul baru melalui program pemuliaan tanaman, yang antara lain bertujuan meningkatkan kuantitas dan kualitas hasil, ketahanan pascapanen, ketahanan hama-penyakit serta ketahanan terhadap lingkungan suboptimal atau marginal (Wattimena 2011; Poerwanto dan Susila 2014). Menurut Syukur et al. (2015), kegiatan pemuliaan tanaman penting untuk merakit varietas-varietas unggul baru yang berkemampuan lebih baik dalam menghasilkan biomassa serta menyalurkan ke bagian yang dapat di panen.

Perakitan varietas-varietas dalam pemuliaan tanaman melalui tiga tahap, antara lain perluasan genetik populasi, seleksi, dan uji daya hasil. Sifat fenotipe yang muncul pada tanaman introduksi di daerah asal belum tentu sama dengan daerah lainnya. Hal ini disebabkan adanya interaksi lingkungan dengan individu spesies, sehingga fenotipe yang muncul sesuai dengan lingkungan sekitarnya. Perbedaan fenotipe yang dimunculkan dapat menjadi dasar dalam evaluasi karakter-karakter individu di lingkungan adaptasi yang baru (Acquaah 2007).

Keragaman sifat dibedakan atas sifat kualitatif dan sifat kuantitatif. Karakter kualitatif atau morfologi merupakan variasi yang langsung dapat diamati. Pengelompokan berdasarkan sifat kualitatif lebih mudah, karena sebarannya diskret dan dapat dilakukan melalui karakter morfologi (Kouassi et al. 2012). Berdasarkan hal tersebut maka dilakukan penelitian yang bertujuan untuk mengidentifikasi karakter kualitatif galurgalur uji cabai rawit IPB di Kota Palembang.

\section{MATERI DAN METODE}

Penelitian dilaksanakan di Kecamatan Sematang Borang, Kota Palembang pada bulan September 2018 sampai dengan April 2019. Bahan yang digunakan adalah 11 galur uji cabai rawit IPB, 5 varietas pembanding, media semai, pupuk kandang, mulsa plastik hitam perak, pupuk NPK, Urea, KCl, SP-36, dan pestisida.. Peralatan yang digunakan adalah baki semai, ajir, gembor, meteran, timbangan, tali rafia, jangka sorong serta alat lainnya yang terkait dalam penelitian. 
Penelitian dilaksanakan menggunakan Rancangan Acak Kelompok (RAK) dengan perlakuan 11 galur uji cabai rawit (F5285290-237-6-1, F6285290-6-101-1, F5285290-290-2-1, F5285290-290-9-1, F5285290-290-9-3, F5321290-40-2-1, F5285290-123-6-15, F6321290-252-10-8-4, F5285290-38-6-3, F6321290-252-10-8-23, F6321290-252-10-8-7). Sementara itu, varietas pembanding yang digunakan adalah varietas Bonita IPB, C290, C285, C295 dan C321. Galur uji yang digunakan merupakan turunan F5 dan F6 hasil persilangan tetua yang dijadikan varietas pembanding (Tabel 1). Seluruh galur ini merupakan hasil persilangan tim Pusat Kajian Hortikultura Tropika Institut Pertanian Bogor. Setiap perlakuan diulang tiga kali sehingga didapatkan 33 satuan percobaan. Satu satuan percobaan berupa plot berukuran $5 \mathrm{~m} \times 1 \mathrm{~m}$ yang terdiri atas 10 tanaman contoh, dengan jarak tanam $50 \mathrm{~cm}$ x $50 \mathrm{~cm}$.

Karakter kualitatif yang diamati berdasarkan deskriptor cabai (IPGRI 1995) dan Direktorat Pembenihan Hortikultura (2017) untuk tanaman cabai.

Tabel 1. Daftar tetua cabai rawit galur uji dan varietas pembanding

\begin{tabular}{lc}
\hline Galur uji & Tetua \\
\hline F5285290-237-6-1 & Tabasco X Inul \\
F6285290-6-10-1-1 & Cakra Putih X Inul \\
F5285290-290-2-1 & Cakra Putih X Inul \\
F5285290-290-9-1 & Cakra Putih X Inul \\
F5285290-290-9-3 & Cakra Putih X Inul \\
F5321290-40-2-1 & Tabasco X Inul \\
F5285290-123-6-15 & Cakra Putih X Inul \\
F6321290-252-10-8-4 & Tabasco X Inul \\
F5285290-38-6-3 & Cakra Putih X Inul \\
F6321290-252-10-8-23 & Cakra Putih X Inul \\
\hline Varietas Pembanding & Tetua \\
\hline Bonita IPB & Bonita IPB \\
C290 & Inul \\
C295 & Taruna \\
C321 & Tabasco X Inul \\
C285 & Cakra Putih \\
\hline
\end{tabular}

\section{HASIL DAN PEMBAHASAN}

Keragaman sifat fenotipe yang muncul disebabkan adanya interaksi lingkungan dengan individu. Menurut Syukur et al. (2012), karakter kualitatif merupakan karakter yang dikendalikan oleh gen sederhana dan tidak atau sedikit sekali dipengaruhi oleh lingkungan, sehingga sifat kualitatif cabe rawit tidak terlalu beragam.

Hasil pengamatan bentuk dan warna batang menunjukkan $100 \%$ galur uji cabai rawit memiliki bentuk dan warna batang yang sama, yaitu bentuk batang bersudut dengan warna batang hijau muda (Tabel 2). Karakter bentuk batang diamati pada batang utama (IPGRI 1995). Penentuan bentuk batang bersifat cukup obyektif

Demikian pula dengan bentuk daun. Bentuk daun cabai menurut IPGRI (1995) terdiri atas tiga bentuk, yaitu deltoid, ovate, dan lanceolate. Bentuk daun pada 11 genotipe cabai rawit yang teramati $100 \%$ memiliki bentuk daun yang cenderung ovate (bentuk daun agak oval). Warna daun tiga galur uji $(27,3 \%)$, yaitu galur F5285290-237-6-1, F6285290-6-101-1 dan F5285290-123-6-15 berwarna hijau, berbeda dengan $72,7 \%$ galur uji lainnya yang memiliki daun berwarna hijau tua (Tabel 2). 
Tabel 2. Warna daun, bentuk daun, warna batang, dan bentuk batang beberapa galur uji cabai rawit IPB

\begin{tabular}{lcccc}
\hline Galur uji & Bentuk batang & Warna batang & Warna daun & Bentuk daun \\
\hline F5285290-237-6-1 & Bersudut & Hijau muda & Hijau & Oval \\
F6285290-6-10-1-1 & Bersudut & Hijau muda & Hijau & Oval \\
F5285290-290-2-1 & Bersudut & Hijau muda & Hijau tua & Oval \\
F5285290-290-9-1 & Bersudut & Hijau muda & Hijau tua & Oval \\
F5285290-290-9-3 & Bersudut & Hijau muda & Hijau tua & Oval \\
F5321290-40-2-1 & Bersudut & Hijau muda & Hijau tua & Oval \\
F5285290-123-6-15 & Bersudut & Hijau muda & Hijau & Oval \\
F6321290-252-10-8-4 & Bersudut & Hijau muda & Hijau tua & Oval \\
F5285290-38-6-3 & Bersudut & Hijau muda & Hijau tua & Oval \\
F6321290-252-10-8-23 & Bersudut & Hijau muda & Hijau tua & Oval \\
F6321290-252-10-8-75 & Bersudut & Hijau muda & Hijau tua & Oval \\
\hline
\end{tabular}

Seluruh galur uji dan galur pembanding cabai rawit memiliki warna bunga, kelopak dan mahkota bunga yang sama, yaitu bunga berwarna putih kehijauan dengan kelopak bunga berwarna hijau dan mahkota bunga berwarna putih kehijauan (Tabel 3).

Tabel 3. Warna bunga, kelopak bunga, mahkota bunga, kepala putik dan benang sari beberapa galur uji cabai rawit IPB

\begin{tabular}{|c|c|c|c|c|c|}
\hline Galur uji & $\begin{array}{l}\text { Warna } \\
\text { bunga }\end{array}$ & $\begin{array}{c}\text { Warna } \\
\text { kelopak }\end{array}$ & $\begin{array}{c}\text { Warna } \\
\text { mahkota } \\
\text { bunga }\end{array}$ & $\begin{array}{l}\text { Warna kepala } \\
\text { putik }\end{array}$ & $\begin{array}{c}\text { Warna benang } \\
\text { sari }\end{array}$ \\
\hline F5285290-237-6-1 & Putih kehijauan & Hijau & Putih kehijauan & Hijau muda & Ungu \\
\hline F6285290-6-10-1-1 & Putih kehijauan & n Hijau & Putih kehijauan & Hijau & Putih bergaris ungu \\
\hline F5285290-290-2-1 & Putih kehijauan & Hijau & Putih kehijauan & Kuning kehijauan & Putih bergaris ungu \\
\hline F5285290-290-9-1 & Putih kehijauan & Hijau & Putih kehijauan & Hijau & Putih bergaris ungu \\
\hline F5285290-290-9-3 & Putih kehijauan & Hijau & Putih kehijauan & Hijau & Putih bergaris ungu \\
\hline F5321290-40-2-1 & Putih kehijauan & Hijau & Putih kehijauan & Kuning & Ungu \\
\hline F5285290-123-6-15 & Putih kehijauan & Hijau & Putih kehijauan & Hijau muda & Putih bergaris ungu \\
\hline F6321290-252-10-8-4 & Putih kehijauan & n Hijau & Putih kehijauan & Kuning & Ungu \\
\hline F5285290-38-6-3 & Putih kehijauan & Hijau & Putih kehijauan & Hijau & Putih bergaris ungu \\
\hline F6321290-252-10-8-23 & Putih kehijauan & n Hijau & Putih kehijauan & Hijau muda & Ungu \\
\hline F6321290-252-10-8-75 & Putih kehijauan & A Hijau & Putih kehijauan & Hijau & Ungu \\
\hline
\end{tabular}

Kepala putik galur uji cabai rawit memiliki warna yang bervariasi dari hijau muda, hijau, kuning kehijauan dan kuning. Dari kesebelas galur, tiga galur $(27,3 \%)$ memiliki kepala putik berwarna hijau muda (galur F5285290-237-6-1, F5285290-123-6-15 dan F6321290-25210-8-23), lima galur (45,5\%) berwarna hijau (galur F6285290-6-10-1-1, F5285290-290-9-1, F5285290-290-9-3, F5285290-38-6-3, dan F6321290-25210-8-75), satu galur F5285290-290-2-1 $(9,1 \%)$ berwarna kuning kehijauan dan dua galur F5321290-40-2-1 dan F6321290-252-10-8-4 (18,2\%) dengan kepala putik berwarna kuning (Tabel 3). Menurut IPGRI (1995) karakter warna kepala putik diamati pada kepala putik yang belum anthesis, sehingga pengamatan warna anther dilakukan pada bunga yang kuncup besar hingga baru mekar agar dapat memperoleh kepala putik yang segar.

Berdasarkan warna benang sari (Tabel 3), sebanyak $45,5 \%$ galur uji memiliki warna benang sari berwarna ungu (galur F5285290-237-6-1, F5321290-40-2-1, F6321290-252-10-8-4, F6321290-252-10-8-23 dan F6321290252-10-8-75) dan 54,5\% berwarna putih 
bergaris ungu (F6285290-6-10-1-1, F5285290-290-2-1, F5285290-290-9-1, F5285290-290-9-3, F5285290-123-6-15 dan F5285290-38-6-3).

Terdapat perbedaan warna antara buah muda dengan buah tua. Warna buah muda bervariasi antara putih $(18,2 \%)$ yaitu pada galur F5285290-237-6-1 dan F5285290-38-6-3, hijau kekuningan $(18,2 \%)$ pada galur F6285290-6-10-1-1 dan F5285290-290-2-1 serta hijau muda $(63,6 \%)$ pada galur F5285290-290-9-1, F5285290-290-9-3, F5321290-40-2-1, F5285290-123-6-15, F6321290-252-10-84, F6321290-252-10-8-23 dan F6321290-
252-10-8-75. Buah tua berwarna merah tua pada galur F5285290-237-6-1(9,1\%), merah terang pada galur F6321290-25210-8-75 (9,1\%), dan sembilan galur lainnya $(81,8 \%)$ memiliki buah tua berwarna merah (Tabel 4). Secara umum, konsumen sayuran menganggap faktor warna kulit merupakan faktor terpenting dalam menilai atau membeli buah cabai. Konsumen rata-rata menyukai warna buah masak yang merah menyala atau warna merah tua (Adiyoga 2012; Rahayu dan Purnamaningsih 2018).

Tabel 4. Warna buah muda, warna buah tua, bentuk buah, bentuk biji, dan warna biji beberapa galur uji cabai rawit IPB

\begin{tabular}{|c|c|c|c|c|c|}
\hline Galur uji & $\begin{array}{c}\text { Warna } \\
\text { buah muda }\end{array}$ & $\begin{array}{c}\text { Warna } \\
\text { buah tua }\end{array}$ & Bentuk buah & $\begin{array}{c}\text { Bentuk } \\
\text { biji }\end{array}$ & $\begin{array}{c}\text { Warna } \\
\text { Biji }\end{array}$ \\
\hline F5285290-237-6-1 & Putih & Merah tua & Segitiga & Bulat pipih & Kekuningan \\
\hline F6285290-6-10-1-1 & Hijau kekuningan & Merah & Segitiga & Bulat pipih & Kekuningan \\
\hline F5285290-290-2-1 & Hijau kekuningan & Merah & Segitiga sempit & Ginjal & Putih kekuningan \\
\hline F5285290-290-9-1 & Hijau muda & Merah & Segitiga & Bulat pipih & Putih kekuningan \\
\hline F5285290-290-9-3 & Hijau muda & Merah & Segitiga & Ginjal & Kekuningan \\
\hline F5321290-40-2-1 & Hijau muda & Merah & Segitiga sempit & Ginjal & Kekuningan \\
\hline F5285290-123-6-15 & Hijau muda & Merah & Segitiga & Bulat pipih & Putih kekuningan \\
\hline F6321290-252-10-8-4 & Hijau muda & Merah & Segitiga & Bulat pipih & Kekuningan \\
\hline F5285290-38-6-3 & Putih & Merah & Segitiga & Bulat pipih & Kekuningan \\
\hline F6321290-252-10-8-23 & Hijau muda & Merah & Segitiga & Bulat pipih & Kekuningan \\
\hline F6321290-252-10-8-75 & Hijau muda & Merah terang & Segitiga & Bulat pipih & Kekuningan \\
\hline
\end{tabular}

Data pada Tabel 3 menunjukkan terdapat dua macam bentuk buah berdasarkan potongan melintang buah, yaitu bentuk segitiga atau segitiga sempit. Dua galur cabai rawit $(18,2 \%)$ memiliki buah berbentuk segitiga sempit, yaitu galur F5285290-290-2-1 dan F5321290-40-2-1, sedangkan sembilan galur lainnya $(81,8 \%)$ memiliki buah berbentuk segitiga.

Bentuk biji cabai rawit yang diuji ada dua macam, yaitu bentuk ginjal atau bulat pipih. Tiga galur cabai rawit $(27,27 \%)$ yang memiliki bentuk biji ginjal adalah galur F5285290-290-2-1, F5285290-2909-3 dan F5321290-40-2-1 sedangkan delapan galur lainnya $(72,72 \%)$ memiliki biji berbentuk bulat pipih (Tabel 4).

Warna biji galur uji cabai rawit antara kekuningan atau putih kekuningan. Tiga galur $(27,27 \%)$ memiliki biji berwarna putih kekuningan dan biji delapan galur $(72,72 \%)$ berwarna kekuningan. Adapun galur yang memiliki biji berwarna putih kekuningan adalah galur F5285290-290-2-1, F5285290-2909-1 dan F5285290-123-6-15 (Tabel 4).

\section{KESIMPULAN}

Keragaman karakter kualitatif 11 genotipe cabai rawit yang diuji relative kecil, karena dikendalikan oleh satu atau dua gen yang dominan terhadap penampilan. Hasil evaluasi menunjukkan $100 \%$ galur uji dan galur pembanding cabai rawit memiliki kesamaan dalam bentuk batang bersudut, warna batang hijau muda, bentuk daun oval, warna bunga putih kehijauan, kelopak dan mahkota bunga berwarna hijau dan putih 
kehijauan. Warna daun galur yang diteliti hijau dan hijau muda. Kepala putik berwarna hijau muda, hijau, kuning kehijauan dan kuning. Benang sari berwarna ungu dan putih bergaris ungu. Buah cabai muda memiliki warna kulit yang berbeda dengan buah tua. Warna kulit buah muda bervariasi antara putih, hijau kekuningan dan hijau muda, sedangkan warna kulit buah tua bervariasi antara merah, merah terang dan merah tua.

\section{DAFTAR PUSTAKA}

Acquaah G. 2007. Principle of Plant Genetics and Breeding. New Jersey: Wiley-Blackwell.

Adiyoga WN. 2012. Analisis konjoin preferensi konsumen terhadapatribut produk kentang, bawang merah, dan cabai merah. Jurnal Hortikulura. 22(3): 292-302.

[BPS] Badan Pusat Statistik. 2017. Produksi Cabai Besar, Cabai Rawit, dan Bawang Merah dalam Angka Tahun 2015.

Direktorat Jenderal Hortikultura. 2008.

Membangun Hortikultura Berdasarkan Enam Pilar Pengembangan.

http://hortikultura.go.id. [7 $\quad$ Agustus 2018].

[IPGRI] International Plant

Genetic Resources Institute.

1995. Descriptor for

Capsicum(Capsicum spp.). IPGI, AVRDC, CATIE, Italia.

Kouassi CK, RK Nevry, LY Guillaume, ZN Yesse, M Koussemon, T Kablan, K. Kouassi. 2012. Profiles of bioactive compounds of some pepper
Bentuk potongan melintang buah segitiga sempit. Bentuk biji ginjal atau bulat pipih, dengan warna biji kekuningan dan putih kekuningan.

\section{UCAPAN TERIMA KASIH}

Ucapan terima kasih disampaikan kepada Pusat Kajian Hortikultura Tropika Institut Pertanian Bogor (PKHT IPB) atas kerjasama penelitian.

fruit (Capsicum annuum L.) varieties grown in Coted'ivoire. Innovative Romanian Food Biotechnol. 11: 2331.

Pusat Data dan Sistem Informasi Kementerian Pertanian. 2016. Outlook Komoditas Pertanian Sub Sektor Hortikultura. Kementerian Pertanian.

Poerwanto R, AD Susila. 2014. Teknologi Hortikultura. Seri 1 Hortikultura Tropika. Bogor: IPB Press.

Rahayu SF, SL Purnamaningsih. 2018. Uji daya hasil pendahuluan cabai rawit (Capsicum frutescens). Jurnal Produksi Tanaman. 6(3): 386-391.

Safira EU. 2011. Jurus Sukses Bertanam 20 Sayuran di Pekarangan Rumah. Klaten: Ganesa Study Center.

Setiadi. 1999. Jenis dan Budidaya Cabai Rawit. Jakarta: Penebar Swadaya.

Syukur M, S Sujiprihati, R Yunianti. 2010. Teknik Pemulian Tanaman Cabai. Bogor: Institut Pertanian Bogor.

Wattimena, G.A. 2011. Bioteknologi dalam Pemuliaan Tanaman. IPB Press. Bogor. 